\title{
STANDARDIZATION OF THE SPORE DENSITY OF AM FUNGAL INOCULUM FOR EFFECTIVE COLONIZATION
}

\section{SARANYA KUPPUSAMY1* AND KUMUTHA K. ${ }^{2}$}

Dept. of Agricultural Microbiology, Tamil Nadu Agricultural University, Coimbatore- 641 003, Tamil Nadu, India.

*Corresponding Author: Email- saran.miles2go@gmail.com¹, kkumuthatnau@yahoo.com²

Received: December 01, 2011; Accepted: March 01, 2012

\begin{abstract}
A pot culture experiment was conducted to develop quality standards for the Arbuscular Mycorrhiza (AM) inoculum in terms of spore density in order to ensure the efficacy of the AM product when used for crop production as a P mobilizing biofertilizer. Plant growth parameters like root volume and total plant dry weight of maize (PEHM5) which was used as trap crop skyrocketed to its maximum when inoculated with 5-6 spores $\mathrm{g}^{-1}$ of AM inoculum. Effective root colonization of $100 \%$ was recorded in maize when $5-6$ spores, was present. Total root length colonization of the maize variety PEHM5 was registered to be more than $90 \%$, when treated with an AM inoculum containing 5-6 spores $\mathrm{g}^{-1}$. Moreover, a significant increase of the spore number was observed, when sterilized vermiculite $+10 \%$ soil was used as substrate for the AM inoculum production with increased spore density of 5-6 spores $\mathrm{g}^{-1}$. Thus, spore density of 5-6 spores was standardized to be one of the quality control parameter of AM inoculum which can be adopted to certify a high quality AM product for crop production.
\end{abstract}

Key words- Arbuscular mycorrizal (AM) fungi, inoculum, spore density and colonization

Citation: Saranya Kuppusamy and Kumutha K. (2012) Standardization of the Spore Density of AM Fungal Inoculum for Effective Colonization. International Journal of Agriculture Sciences, ISSN: 0975-3710 \& E-ISSN: 0975-9107, Volume 4, Issue 2, pp- 176-181.

Copyright: Copyright@2012 Saranya Kuppusamy and Kumutha K. This is an open-access article distributed under the terms of the Creative Commons Attribution License, which permits unrestricted use, distribution, and reproduction in any medium, provided the original author and source are credited.

\section{Introduction}

Arbuscular mycorrhizal (AM) fungi have shown to have a pivotal role in agriculture and land reclamation (Klironomos et al., 2002). AM inoculation of plants in field offers the possibility of reducing fertilizer and pesticide application and it improves the resistance to diseases caused by soil borne pathogens. Therefore, AM fungi are gaining popularity as 'Biofertilizer', 'Bioprotectant' and 'Biocontrol agent' and the industry of mycorrhizal inoculum production is expanding around the world (Feldmann and Grolkan, 2002). The growing number of new small to medium sized companies (SME's) around the world producing inocula of mycorrhizal fungi has increased in the last decade. Still, there are major problems in bringing high quality and fit for purpose AM fungal products to target markets. Because AM fungi are obligate symbionts, the production of AM fungal inocula of the best quality is still challenging.

Moreover, the quality control of AM inoculum producing companies is not yet under control of independent institutions. Therefore, more accurate methods are required to ensure a high quality and consistent AM inoculant. At present, regulation of the product varies between countries and companies for the AM inoculant and each company still has its specific demands and target markets (Feldmann, 2007). Thus, by formulating quality standards for AM inoculants especially in terms of spore density, since spores of $\mathrm{AM}$ are only instrumental to bring a better colonization in plants and bring in the $\mathrm{P}$ mobilization that aid in ultimate plant growth, it would be more feasible to manipulate these fungi for increased agricultural productivity and plant health assurance, so that the end users can be satisfied by the producers and both will be benefited. Hence, the present investigation was undertaken to develop quality standards for AM inoculant in terms of spore density.

\section{Materials and methods}

This experiment was undertaken to standardize the suitable spore density for arbuscular mycorrhizal fungal inoculum using vermiculite as substrate and maize as host plant under pot culture conditions. 


\section{Production of arbuscular mycorrhizal (AM) mother inoculum for the Study}

The arbuscular mycorrhizal fungal strain of Glomus intraradices (Tamil Nadu Agricultural University, Coimbatore) was obtained and multiplied in the net house at the Department of Agricultural Microbiology, TNAU, Coimbatore. Maize (Zea Mays) was used as host plant to multiply the arbuscular mycorrhizal fungi. Fifty live spores of Glomus intraradices was placed under germinated seedlings of maize into pots containing 1:1 sterile sand: soil mixture. The pots were watered regularly along with a spray of Hogland's plant nutrient solution (once in a week) and infection was allowed to develop in the host plant for atleast three months before the inoculum was harvested. The 'mother' inoculum (containing spores of Glomus intraradices, hyphae and colonized root bits) was obtained by cutting all the roots of host plants to $1 \mathrm{~cm}$ size and mixing it with the pot mixture.

The 'mother' inoculum was used for a series of pot culture experiments conducted to develop the quality standards for arbuscular mycorrhizal inoculum.

\section{Isolation of AM spores from the mother inoculum}

AM spores were isolated using the method of wet sieving and decantation with slight modifications as described by Gerdemann and Nicolson (1963) from the 'mother' inoculum.

About $100 \mathrm{~g}$ of the AM inoculum was taken in a one litre beaker and added with ten times its volume of water ie., water added to the sample in 1:10 ratio. This suspension was stirred vigorously using a glass rod and allowed to settle. The suspension was then decanted or poured through a sieve arrangement from coarse sieve to fine sieve. The sizes of the sieves were arranged as 180 $\mu, 106 \mu$ and $45 \mu$ from top to bottom. This process was repeated several times, until the suspension becomes colourless. The sievings were transferred to a separate beaker and filtered through Whatman No. 1 filter paper. The filter paper was observed under Nikon SMZ - 10 stereozoom microscope for the presence of spores. The young, viable spores of Glomus intraradices were collected using capillary tube into a sterilized vial containing Ringer's solution (Sodium chloride $-5.0 \mathrm{~g}$, Calcium chloride $-0.01 \mathrm{~g}$, Potassium chloride $-0.01 \mathrm{~g}$, Magnesium chloride $-0.01 \mathrm{~g}$ and distilled water $-100 \mathrm{ml}$ ) and were maintained at $4^{\circ} \mathrm{C}$ until use.

\section{Treatment Details \\ Treatments}

- $\mathrm{T}_{1}$ - Uninoculated control

- $T_{2}-1$ to 3 spores $g^{-1}$ of AM inoculum

- $T_{3}-5$ to 6 spores $g^{-1}$ of $A M$ inoculum

- $T_{4}-10$ to 12 spores $g^{-1}$ of AM inoculum

Levels

- $\mathrm{S}_{1}$ - Vermiculite alone

- $\mathrm{S}_{2}$-Vermiculite $+10 \%$ sterile soil

- The treatments were replicated five times and were arranged in completely randomized block design.

\section{Substrate}

Raw vermiculite (Grade IV) obtained from Tamil Nadu Minerals, Chennai was used in this experiment, with and without the amendment of $10 \%$ sterile field soil collected from Eastern Block, TNAU Coimbatore. The substrate was sterilized at $15 \mathrm{lbs}$ pressure for 30 minutes and used for the study. The substrates as per the treatments were filled in black pots $(15 \times 15 \mathrm{~cm})$, about $1 \mathrm{~kg} \mathrm{pot}^{-1}$.

\section{Preparation of AM inoculum}

About $5 \mathrm{~g}$ of sterile vermiculite was mixed with the respective quantity of AM spores of Glomus intraradices isolated from the 'mother' inoculum and was used as the inoculum for the conduct of this experiment. AM inoculum developed with different spore densities were applied approximately $2.5 \mathrm{~cm}$ below the pot mix. The rate of inoculum was $5 \mathrm{~g} \mathrm{pot}^{-1}$ filled with $1 \mathrm{~kg}$ of substrate.

\section{AM multiplication and sampling}

Seeds of maize (variety PEHM 5) obtained from the State Department of Agriculture, Thondamputhur was used for the study. The seeds were surface sterilized with 0.1 percent mercuric chloride for 3 minutes before sowing and were sown $3 \mathrm{~cm}$ below the surface of the substrate. About five plants were maintained in each pot. The pots were watered regularly. Once in 15 days each pot was given with $20 \mathrm{ml}$ of 2x Hoagland solution minus phosphate (Hoagland and Arnon, 1950). Plant samples were taken from each treatment on 45 and 60 days after sowing.

\section{Observations}

Root volume and plant dry weight were recorded. Arbuscular mycorrhizal colonization in root, spore density and total microbial load in the substrates were also estimated. In addition, total root length colonization of maize by AM was calculated.

\section{Plant dry weight}

The uprooted plants were sun dried for one day and then dried in hot air oven at 60 to $70^{\circ} \mathrm{C}$ for three consecutive days till the constant dry weight was obtained. The dry weights were recorded and expressed in g plant $^{-1}$.

\section{Root volume}

Volume of the root samples were determined by volume displacement analysis (Burdette, 1979). Initially, a graduated cylinder that would be large enough to fit the root being measured was selected. After filling the graduated cylinder with water to a satisfactory level, the volume of water alone was recorded. After that, the root was carefully placed in the graduated cylinder and the volume of water and root was recorded. In order to calculate the volume of the irregularly shaped root, the volume of the water alone was subtracted from the volume of the water and root and the values were expressed in $\mathrm{cm}^{3}$ plant-1.

Per cent AM colonization $=$ Number of root bits colonized

\section{AM fungal colonization in roots of the host plant}

Roots of maize uprooted on $45^{\text {th }}$ and $60^{\text {th }}$ days after sowing were assessed for AM fungal colonization by following root clearing and staining technique developed by Phillips and Hayman (1970).

The uprooted roots were thoroughly washed in tap water to remove any soil or vermiculite particles. The roots were then cut into small bits of about $1 \mathrm{~cm}$ long and immersed in $10 \%$ potassium hydroxide solution. This was autoclaved with $5 \mathrm{lbs}$ pressure for 10 minutes, and washed with water till the brown colour disappeared. Then the roots were immersed in $2 \%$ hydrochloric acid for about 5 to 10 minutes, and the acid was decanted. Tryphan blue $0.05 \%$ 
prepared with lactoglycerol was added $(45 \mathrm{ml}$ of lactic acid +45 $\mathrm{ml}$ of glycerol $+10 \mathrm{ml}$ of distilled water was mixed and added with $0.05 \mathrm{~g}$ Tryphan blue) after fixation with $2 \% \mathrm{HCl}$. After staining, the root bits were kept as such overnight. Observation of the stained root bits for fungal infection under Olympus CX 40 microscope was carried out after destaining the stained roots with lactoglycerol $(1: 1)$ or glycerol $50 \%$ in order to remove the excess stain. Per cent of AM fungal colonization was calculated using the formula,

Per cent AM colonizasion $=\frac{\text { Number of root bits colonized }}{\text { Total number of root bits examined }} \times 100$

\section{Total Root Length colonization (TRLC) in Maize}

Total root length colonized by hyphae, arbuscules and vesicles was estimated by grid line intersection method (McGonigle et al., 1990). Maize roots were stained using tryphan blue stain. For each subsample two to four slides were used. However all the slides for a subsample were treated as a single unit, and not as subsamples. A graticule with a cross hair was prepared and attached in the eye piece. The roots were aligned parallel to the long axis of the slides and observed at magnification of 200x.

The alignment of the roots parallel to the horizontal line of the cross hairs was adjusted to right angle to the long axis of the root by the rotation of the vertical crosshairs. Where the centre of the crosshairs entered a root through an end rather than a side, i.e. the point of exit from the root through its side was taken as the point of intersection. Roots too wide to fit into the field of view at 40x magnification were examined in two or more width portions. The plane of focus was completely moved through the root to examine each intersection and a note of whether the vertical crosshairs actually cut any arbuscules, coils, vesicles and hyphae was made. The number of intersections was counted in the following categories viz., arbuscules, vesicles, coils or hyphae. When the vertical crosshairs cut one or more arbuscules or vesicles, the appropriate category was incremented by one and a similar increment was given for intersections where hyphae only were crossed.

The arbuscular colonization (AC) and other categories (hyphae, coils, vesicles) colonization were calculated by dividing the count for the arbuscules and categories respectively by the total number of intersections examined.

Finally the total root length colonization (TRLC) was calculated using the formula as given below:

$T R L C=A C+V C+H C+C C$

where,

AC- Arbuscular colonization

VC - Vesicular colonization

$\mathrm{HC}$ - Hyphal colonization

CC- Coil colonization

\section{Quantification of the AM spore density}

AM fungal spores were extracted from the rhizosphere substrate of maize by using the Wet sieving and Decantation Technique. Total number of viable spores were counted by following the procedure as follows.

Sievings from each sieve $(180 \mu$ and $106 \mu)$ collected separately in to small beakers was transferred again into the fine sieve ( 45 $\mu)$. The sievings from fine sieve was collected using a fine get of water into a griddled filter paper funnel so as to remove the excess water. The filter paper was griddled at one half of the sheet and it was folded in such a way that the marked portion was the receiving surface during filtration. After the filtration the filter paper was removed gently and spreaded on a bigger size Petriplate with spores \& other debris and observed under stereozoom microscope. Presence of viable spores were counted by moving the Petriplate and the total number of viable spores were calculated corresponding to the weight of soil taken for analysis and the result was expressed as number $100 \mathrm{~g}^{-1}$ of the sample sieved.

\section{Statistical analysis}

The data obtained were analyzed by a three and two factorial analysis of variance $(p=0.05)$ wherever possible, with days after sowing, treatments and substrates as experimental factors using AGRES software, with mean separation by Least significant difference (LSD) as per the methods detailed by the Panse and Sukhatme (1978). The analysis for microbial population count was based on the log and arcsine transformed values.

\section{Result}

With the objective of standardizing the spore density of AM fungal inoculum for effective colonization, a pot culture study was conducted using maize (PEHM 5) as host plant and vermiculite, vermiculite $+10 \%$ soil as substrate materials.

\section{Root volume and total dry weight}

A critical examination of the data presented in Table 1 indicated that inoculation of AM spores exhibited significant increase in root volume and total dry weight of maize grown in either vermiculite alone or with $10 \%$ soil amendment in vermiculite at 45 and 60 days after plant growth. Progressive increase in root volume was noticed with an increase in age of the crop (Plate 1). At each range of spore density, the increase in root volume was observed and it ranges from 2.5 to $3.0 \mathrm{~cm}^{3}$ when grown in vermiculite and 2.8 to $3.1 \mathrm{~cm}^{3}$ when grown in vermiculite $+10 \%$ soil, recording 47.0 to 76.4 per cent and 64.7 to 82.3 per cent increase over control respectively at 60 days of plant growth. There were no significant difference between the superior treatments that received 5 to 6 spores $g^{-1}\left(T_{3}\right)$ and 10 to 12 spores $g^{-1}\left(T_{4}\right)$ of AM inoculum. The treatment which received 1 to 3 spores $g^{-1}\left(T_{2}\right)$ was significantly lower from $\mathrm{T}_{3}$ and $\mathrm{T}_{4}$ when grown in vermiculite and vermiculite + $10 \%$ soil. The interaction effects were not significant.

Additionally, AM inoculum containing a spore density of 10 to 12 spores $\mathrm{g}^{-1}$ was superior, which influenced the total dry weight of maize at all stages of the crop growth. It recorded the maximum of $6.2 \mathrm{~g}$ in vermiculite, $6.8 \mathrm{~g}$ in vermiculite amended with $10 \%$ field soil with 129.6 and 151.8 per cent increase respectively over control at 45 days after sowing. The similar trend was maintained on 60 days. The interaction effect between days and substrates was observed not significant.

Additionally, AM inoculum containing a spore density of 10 to 12 spores $\mathrm{g}^{-1}$ was superior, which influenced the total dry weight of maize at all stages of the crop growth. It recorded the maximum of $6.2 \mathrm{~g}$ in vermiculite, $6.8 \mathrm{~g}$ in vermiculite amended with $10 \%$ field soil with 129.6 and 151.8 per cent increase respectively over control at 45 days after sowing. The similar trend was maintained on 
60 days. The interaction effect between days and substrates was observed not significant.

\section{AM fungal colonization in roots of Maize}

As per the method of root clearing and staining root colonization was assessed. The results presented in Table 2 tend to indicate a sort of significant increase on root colonization of maize when inoculated with varying levels of AM spores at both the stages of plant growth. AM inoculum application recorded root colonization of 88 to 95 per cent at 45 days of plant growth in vermiculite. When $10 \%$ field soil was amended with vermiculite the root colonization of maize by AM fungi was still enhanced upto 96 per cent on 45 days and 100 per cent on 60 days. Inoculation of AM spores at 10 to 12 spores $\mathrm{g}^{-1}$ recorded maximum root colonization (Plate 2). However, there were no significant difference between the superior treatment that received 10 to 12 spores $\mathrm{g}^{-1}$ and 5 to 6 spores $\mathrm{g}^{-1}$ of $\mathrm{AM}$ inoculum. The interaction effects between treatments and days, treatments and substrates were observed significant.

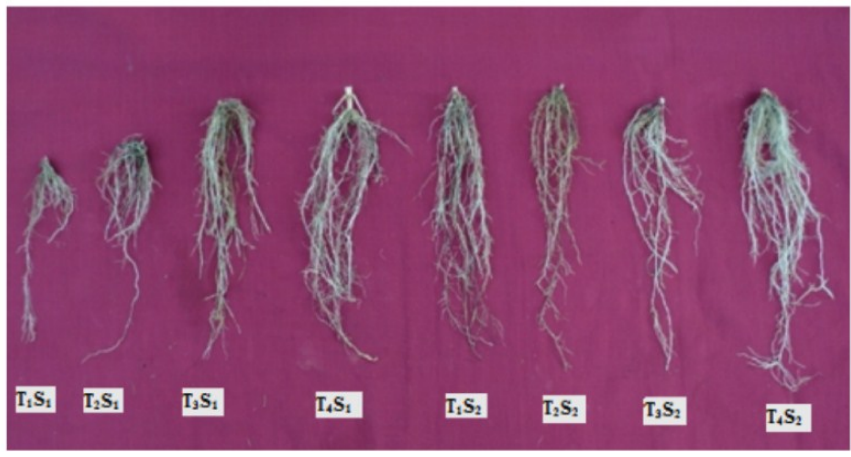

$\mathrm{NT}_{1}$ - Uninoculated control

$\mathrm{T}_{2}-1$ to 3 spores $\mathrm{g}^{-1}$ of AM inoculum

$\mathrm{CT}_{3}-5$ to 6 spores $\mathrm{g}^{-1}$ of $\mathrm{AM}$ inoculum

e $\mathrm{S}_{1}$ - Sterile vermiculite alone

$\mathrm{eT}_{4}-10$ to 12 spores $\mathrm{g}^{1}$ of $\mathrm{AM}$ inoculum

Plate 1- Effect of AM inoculum with different spore densities on the root volume of Maize

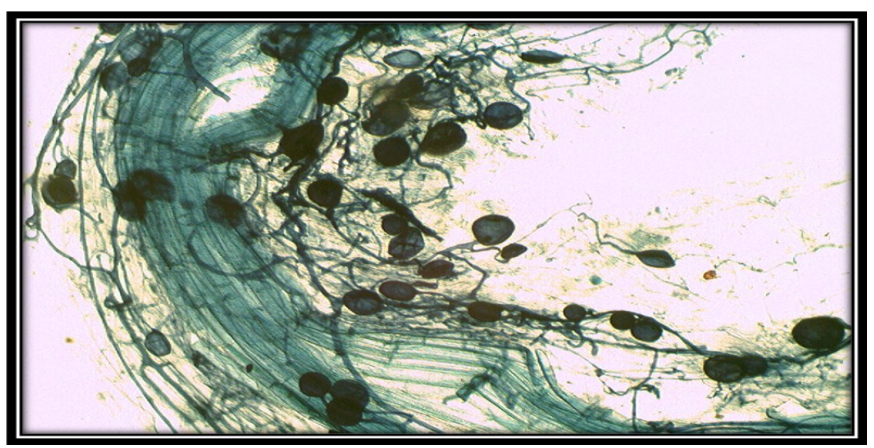

Plate 2- Effect of $A M$ inoculum with 10 to 12 spores g-1 $^{-1}$ on root colonization of Maize

\section{Assessment of total root length colonization of Maize}

Total root length colonized by hyphae, arbuscules, coils and vesicles of AM fungi was estimated by grid line intersection method (Mc Gonigle et al., 1990) at 60 days after sowing. The results showed that among the four treatments analysed, $\mathrm{T}_{4}$ which received 10 to 12 spores $\mathrm{g}^{-1}$ of AM inoculum had significantly maxi- mum AM fungal total root length colonization (90 per cent) followed by $T_{3}$ that received 5 to 6 spores $\mathrm{g}^{-1}$ of AM inoculum (88 per cent) when vermiculite was used as the substrate material (Table 3). Similarly, still further significantly enhanced total root length colonization was recorded in the treatment $\mathrm{T}_{4}$ (98 per cent), followed by $\mathrm{T}_{3}$ (96 per cent) when vermiculite $+10 \%$ soil was used as the substrate material. Uninoculated control had no AM fungal colonization. The interaction effect between treatments and substrates was significant.

\section{Viable spore count of Glomus intraradices in the treated sub- strate}

The spore density was found to vary in each treatment. Viable spore numbers of AM fungi in substrate was significantly influenced with the range of live spores present in the AM inoculum (Figure 1). Among the substrates used, vermiculite $+10 \%$ soil recorded maximum viable spore count compared to vermiculite especially at 60 days after sowing.

Among the substrates sampled at 60 days after plant growth, addition of $A M$ inoculum containing 10 to 12 spores $\mathrm{g}^{-1}$ marked a highest viable spore density of 145 spores $100 \mathrm{~g}^{-1}$ vermiculite followed by the addition of 5 to 6 and 1 to 3 spores $\mathrm{g}^{-1}$ with 133 and 115 spores $100 \mathrm{~g}^{-1}$ vermiculite respectively. In the same way vermiculite $+10 \%$ soil that received 10 to 12,5 to 6 and 1 to 3 spores $\mathrm{g}$ ${ }^{1}$ showed 148, 145 and 124 spores $100 \mathrm{~g}^{-1}$ respectively. There were no significant differences between days and substrates followed by treatments, days and substrates.

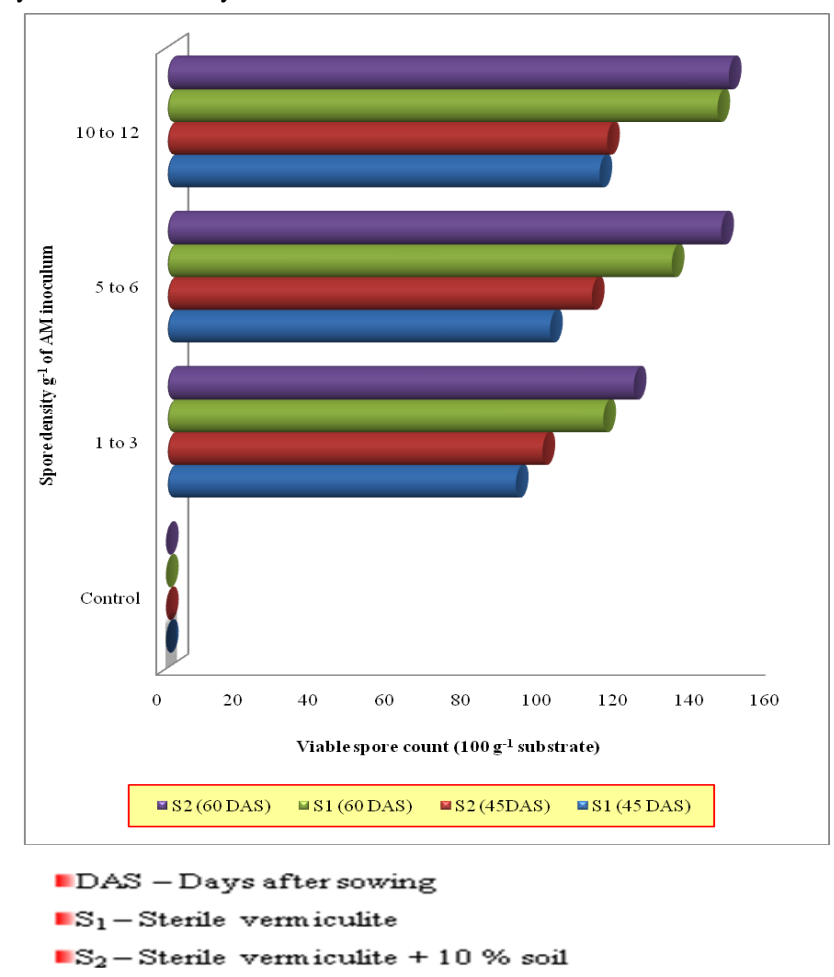

Fig. 1- Effect of AM inoculum with various levels of spore densities on the viable spore count of Glomus intraradices

\section{Discussion}

Infected root segments, infective propagules and spores isolated from open pot cultures of AM fungi inoculated plants have been 
the usual source of AM inoculum for commercial purpose (Sylvia et al., 1993). Spores of AM are the important component of inoculum and are more suitable for large scale production as well as for biochemical and molecular investigations of the AM symbiosis (Thompson, 1987). Hence a preliminary attempt was undertaken to standardize the spore density of AM inoculum for effective colonization using vermiculite and vermiculite $+10 \%$ soil as substrates and maize (cultivar PEHM 5) as host plant. Three different levels of spore densities were tested ( 1 to 3,5 to 6 and 10 to 12 spores $\mathrm{g}^{-1}$ of AM inoculum).

With respect to root volume, $\mathrm{T}_{4}$ (10 to 12 spores $\mathrm{g}^{-1}$ of AM inoculum) recorded the highest. The similar trend was observed in total dry weight of maize also. The results showed that both $T_{4}$ and $T_{3}$ (5 to 6 spores $\mathrm{g}^{-1}$ of AM inoculum) significantly improved the growth of maize and were not statistically significant from each other in their ability to stimulate root volume and total plant dry weight. Similarly, maximum root colonization, total root length colonization and viable spore count was observed to be maximum in $T_{4}$ followed by $T_{3}$ at 60 days when vermiculite amended with 10 $\%$ soil was used as the substrate for plant growth.

In the present investigation, amendment of $10 \%$ soil in sterile vermiculite was found more suitable for AM fungal production and colonization, rather than vermiculite alone. The lower pore space volume of vermiculite and finer size of soil is an optimal combination for AM multiplication. For AM production, vermiculite amended with $10 \%$ soil is most preferred since soil act as a nutrient supplement for the host plant grown in vermiculite. Moreover, soil is available in nature abundantly as free and usage of vermiculite $+10 \%$ soil for mass production would be more economical as usage of soil additionally increases the water holding capacity, cation exchange capacity and alter the $\mathrm{pH}$ that will be conducive for AM inoculum production (Feldmann and Idczak, 1994).

Higher level of spore density in the AM inoculum results in maximum sporulation and spore germination which paves way for the massive development of hyphae and root infection by arbuscular mycorrhizal fungi compared to the lower spore density levels and uninoculated control. Enhanced arbuscular mycorrhizal infection by higher spore density had ultimately resulted in increased root surface area which recorded a maximum root volume at 5 to 6 and 10 to 12 spores $\mathrm{g}^{-1}$ of $A M$ inoculum application. The results clearly indicated that AM colonization and sporulation was better in $T_{4}$ and $T_{3}$ with higher growth of host plant.

Several authors have discussed the production and colonization of AM fungi. Hung and Sylvia et al. (1993) reported that colonized roots and viable spores can serve as infective AM inocula. Nopamornbodi et al. (1987) applied 20 AM spores in $10 \mathrm{ml}$ water suspension under each seed of soy bean and obtained increased yield under field condition. Since large scale production of spore is

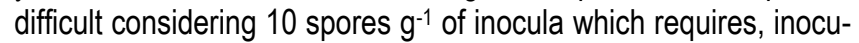
la in $\mathrm{kgs}$ involves sieving the mother inoculum in large quantity to prepare the AM inoculum with desired number of spore density for inoculating field sown crop and is laborious (Douds and Schneck, 1990).

Recent study illustrates that a spore count of 322 per $100 \mathrm{~g}$ of AM inoculum resulted in 80 per cent root colonization in maize at field conditions (Doud et al., 2005). Additionally, Douds et al. (2010) reported that incorporation of $75 \mathrm{~g}$ of inoculum containing 795 mean numbers of spores of G.mosseae at the time of preparation of nursery bags of size $21 \mathrm{~cm}$ diameter $\times 13 \mathrm{~cm}$ height with soil as medium for plant growth, was able to enhance the root length and shoot dry weight of black pepper plants.

\section{Conclusion}

Thus, the result of the present study throws light on the standardized level of spore density that has to be present in the AM inoculum for effective colonization. It is confirmed that when a spore density of 5 to 6 spores are present in $\mathrm{g}^{-1}$ of AM inoculum, it is much more enough to enhance the growth as well as mycorrhizal responses of host plant so that it will ultimately result in the better responses at field level and enhance the crop productivity. Therefore, 5 to 6 spores $\mathrm{g}^{-1}$ of AM inoculum should be considered as one of the quality standard that could ensure a high quality AM inoculum.

\section{References}

[1] Douds D.D. and Schenck N.C. (1990) Appl. Environ. Microbiol., 56: 413-418.

[2] Douds D.D., Nagahashi G. and Hepperly P.R. (2010) Biores. Tech., 1: 2326-2330.

[3] Douds D.D., Nagahashi G., Pfeffer P.E., Kayser W.M. and Reider C. (2005) Can. J. Plant. Sci., 85: 15-21.

[4] Feldmann F. (2007) Feldmann Publications, Birkhauser, Basel, pp. 42.

[5] Gerdemann J.W. and Nicolson P.H. (1963) Trans. Brit. Mycol. Soc., 46: 235-244.

[6] Klironomos J.M. and Hart N.N. (2002) Mycorrhiza, 12: 181184.

[7] McGonigle T.P. and Fitter A.H. (1988) New Phytol., 108: 5965.

[8] Nopamornbodi O., Thamsurakul S. and Charoensook P. (1987) Ann. Rep., Soil Sci., Bangkok : 2: 16.

[9] Panse V.G. and Shukatme P.V. (1978) Indian council of Agric. Res., New Delhi, pp. 327.

[10]Phillips J.M. and Hayman D.S. (1970) Trans. Brit. Mycol. Soc., 13: 31-32.

[11]Sylvia D.M., Hammond L.C., Bennett J.M., Hass J.H. and Linda S.B. (1993) Agron. J., 85: 193-198.

[12]Thompson, J.P. (1987) Australian J. Agric. Res., 38: 847-867. 
Table 1- Effect of AM inoculum with different spore densities on root biomass and total dry weight of Maize

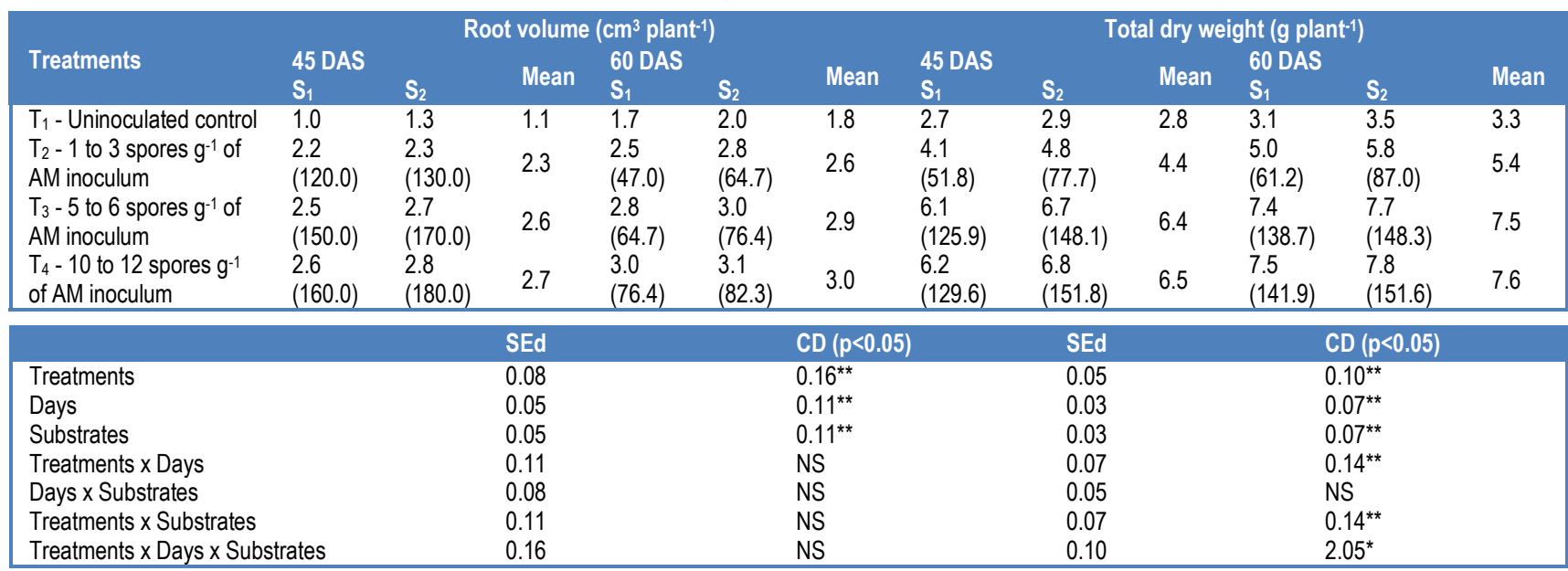

DAS - Days after sowing, S1 - Sterile vermiculite alone, S2 - Sterile vermiculite + $10 \%$ soil, Values represent mean of five replications, Values in paranthesis indicate per cent increase over control, ${ }^{* *}$ - significant at $p<0.01,{ }^{*}$ - significant at $p<0.05, N S$ - not significant.

Table 2- Effect of AM inoculum with different spore densities on root colonization of Maize

\begin{tabular}{|c|c|c|c|c|c|c|}
\hline \multirow[b]{2}{*}{ Treatments } & \multicolumn{6}{|c|}{ AM root colonization (\%) } \\
\hline & $\begin{array}{l}45 \text { DAS } \\
S_{1}\end{array}$ & $S_{2}$ & Mean & $\begin{array}{l}60 \text { DAS } \\
S_{1}\end{array}$ & $S_{2}$ & Mean \\
\hline $\begin{array}{l}T_{1} \text { - Uninoculated control } \\
T_{2}-1 \text { to } 3 \text { spores } g^{-1} \text { of AM inoculum } \\
T_{3}-5 \text { to } 6 \text { spores } g^{-1} \text { of AM inoculum } \\
T_{4}-10 \text { to } 12 \text { spores } g^{-1} \text { of AM inoculum }\end{array}$ & $\begin{array}{l}0 \\
(0.7) \\
88 \\
(70.1) \\
90 \\
(72.0) \\
95 \\
(77.7) \\
\end{array}$ & $\begin{array}{l}0 \\
(0.7) \\
92 \\
(74.6) \\
95 \\
(77.7) \\
96 \\
(80.1)\end{array}$ & $\begin{array}{l}0 \\
(0.7) \\
90 \\
(72.0) \\
93 \\
(74.9) \\
96 \\
(78.9) \\
\end{array}$ & $\begin{array}{l}0 \\
(0.7) \\
95 \\
(77.7) \\
98 \\
(83.0) \\
100 \\
(89.2) \\
\end{array}$ & $\begin{array}{l}0 \\
(0.7) \\
97 \\
(79.2) \\
100 \\
(89.2) \\
100 \\
(89.2)\end{array}$ & $\begin{array}{l}0 \\
(0.7) \\
96 \\
(78.4) \\
99 \\
(86.1) \\
100 \\
(89.2) \\
\end{array}$ \\
\hline & \multicolumn{3}{|l|}{ SEd } & \multicolumn{3}{|c|}{$C D(p<0.05)$} \\
\hline $\begin{array}{l}\text { Treatments } \\
\text { Days } \\
\text { Substrates } \\
\text { Treatments } x \text { Days } \\
\text { Days } \times \text { Substrates } \\
\text { Treatments } \times \text { Substrates } \\
\text { Treatments } \times \text { Days } \times \text { Substrates }\end{array}$ & $\begin{array}{l}1.00 \\
0.86 \\
0.86 \\
1.22 \\
1.02 \\
1.22 \\
1.51\end{array}$ & & & $\begin{array}{l}2.00^{* \star} \\
1.72^{\star *} \\
1.72^{\star *} \\
2.44^{* \star} \\
\text { NS } \\
2.44^{* \star} \\
\text { NS }\end{array}$ & & \\
\hline
\end{tabular}

DAS - Days after sowing, S1 - Sterile vermiculite alone, S2 - Sterile vermiculite $+10 \%$ soil, Values represent mean of five replications, Values in paranthesis indicate the per cent transformed values, ${ }^{* *}$ - significant at $p<0.01$, NS - not significant.

Table 3- Effect of AM inoculum with different spore densities on total root length colonization of Maize at 60 days after sowing

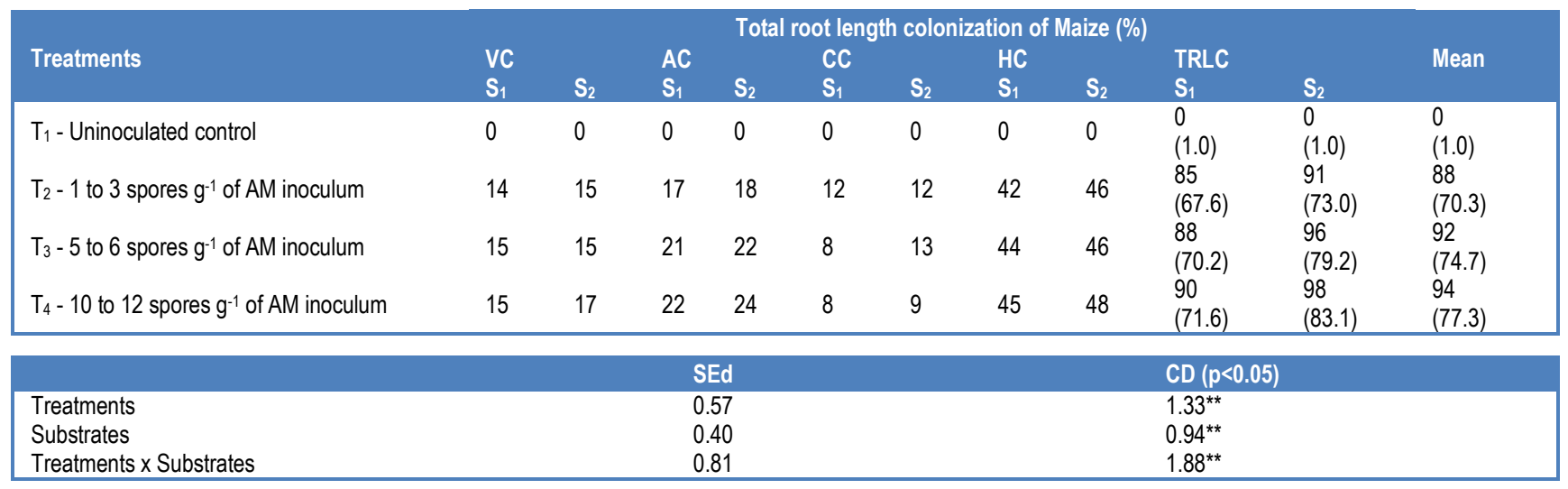

S1 - Sterile vermiculite alone, S2 - Sterile vermiculite + 10 \% soil, VC - Vesicular colonization, AC - Arbuscular colonization, CC - Coil colonization, HC - Hyphal colonization, TRLC - Total root length colonization, Values represent mean of five replications, Values in paranthesis indicate per cent transformed values, ${ }^{* *}$ - significant at $p<0.01$. 